\title{
Imaginarios cinematográficos en torno al menosprecio del indocumentado fronterizo. Entre la xenofobia y la deshumanización
}

\author{
Undocumented $\mid$ Chris Peckover | 2010
}

\author{
Alfonso Ortega Mantecón* \\ Universidad Autónoma Metropolitana, México \\ Sandra Anchondo Pavón \\ Universidad Panamericana, México
}

Recibido 6 de enero 2021; aprobado 3 de marzo 2021

\begin{abstract}
Resumen
El artículo recupera la narrativa del filme Undocumented (Peckover, 2010) para estudiar la violencia hacia los migrantes en la frontera norte (México-Estados Unidos). Entrecruza el contexto de construcción de las políticas migratorias que diseminan un ambiente xenófobo y racista en la frontera. El análisis de Undocumented - bajo la premisa de que el filme parte de esta realidad sociopolítica - modela su crítica antirracista contra la criminalización del indocumentado. Muestra, además, que el propio diseño legislativo promueve el clima de racismo y produce la violencia de tipo estructural y postestructural contra los migrantes. Conecta esta realidad con su representación fílmica a partir de la Ley Arizona o SB1070, cuyo origen y fundamentación contraviene el discurso internacional de los derechos humanos.
\end{abstract}

Palabras Clave: cine | racismo | representación | frontera | indocumentados

Cinematographic Imaginaries Around the Contempt of the Undocumented. Between Xenophobia and Dehumanization

Abstract

The article recovers the narrative of the film Undocumented (Peckover, 2010) to study the violence against the migrants on the northern border (Mexico-United States). It intersects the context of the construction of migratory policies that spread a xenophobic and racist environment on the border. The analysis of Undocumented - under the premise that the film starts with this socio-political reality - models an anti-racist criticism against the criminalization of the migrant. Also, it shows that the legislative design itself promotes the climate of racism and produces structural and poststructural violence against migrants. It connects this reality with its filmic representation based on the Arizona Law or SB1070, whose origin and foundation contravenes the international discourse of human rights.

Keywords: cinema | racism | representation | border | undocumented

Introducción. La frontera: tierra de asimetrías y de violencia

La situación de la frontera México-Estados Unidos ha formado parte de la agenda política de ambos gobiernos en los últimos cuarenta años. El alto número de migrantes, la presencia de grupos criminales organizados, así como la actitud xenófoba y frontalmente racista de algunos políticos y residentes estadounidenses han motivado el surgimiento de diversas políticas migratorias que buscan frenar, ante todo, el paso de migrantes sin documentos a los Estados Unidos, políticas muchas veces cimentadas en el racismo que llegan a atentar contra los derechos humanos y los derechos del migrante.

*alfonsoortman@gmail.com 
Empero, en lugar de conseguir estabilidad en materia migratoria, las medidas tomadas principalmente por Estados Unidos han desencadenado un clima de gran violencia en la franja fronteriza. La frontera entre México y su vecino del norte se ha convertido en una de las más peligrosas del mundo, contando con un promedio de 1.3 personas que fallecen al día intentando cruzarla (Feldmann y Durand, 2008, p. 20). Ya sea como víctimas de la patrulla fronteriza, de grupos paramilitares "cazadores" de migrantes, de cárteles de narcotraficantes, de criminales o de las mismas inclemencias naturales de la región.

Pese a los intentos políticos y de esfuerzo conjunto entre los gobiernos mexicano y estadounidense para regular la migración y evitar el paso de indocumentados, la balanza se inclina considerablemente a favor de Estados Unidos. La asimetría en materia fronteriza entre ambas naciones se aprecia en el hecho de que, para cruzar de México a su vecino del norte, es necesario atravesar una serie de puntos de control antes de que se autorice el paso a los migrantes con documentación vigente. En contraparte, para el ingreso de estadounidenses al territorio mexicano no existen puntos de control fijos ni obligatorios para todos los individuos que deseen cruzar la frontera - por no hablar de la inexistencia de una visa que autorice el ingreso a México-, sólo se cuenta con un semáforo de inspección aduanal completamente aleatorio (Velasco Ortiz y Contreras, 2014, p. 40).

Algo similar se muestra en las cifras de patrullas fronterizas y de defunciones en la zona fronteriza. En 2010, la patrulla fronteriza estadounidense (Border Patrol) contó con cerca de 18,000 agentes encargados de vigilar la zona; mientras que en México, el órgano equiparable, el Grupo Beta, se encontraba conformado por aproximadamente 150 agentes, cuya función principal era proteger a los migrantes americanos que ingresaban al país. La asimetría es evidente también en las muertes de migrantes intentando llegar a los Estados Unidos, se cuentan más de 5,000 entre el año 2000 a 2014 y sabemos que otras tantas han quedado en el anonimato y en el olvido. Por su parte, no se contabiliza ninguna pérdida humana en el intento de los estadounidenses al llegar a México (Velasco Ortiz y Contreras, 2014, p. 41).

Los migrantes que anhelan ingresar a Estados Unidos, lejos de desistir ante el panorama de violencia y hostilidad característico del cruce de la frontera, se han adaptado a los cambios de política fronteriza, gastando importantes sumas de dinero que pagan a los "coyotes" para que los conduzcan a sus destinos por las zonas supuestamente más seguras, aunque se sabe que ello no reduce efectivamente el número de muertes (Feldmann y Durand, 2008, p. 12).

La violencia y discriminación a la que se enfrentan los migrantes en el cruce fronterizo ha sido un tema constantemente recuperado por el cine, contando con un amplio catálogo de producciones que abordan la problemática desde diferentes perspectivas. Tanto ficciones como documentales consiguen abordar temáticas reales, con un importante anclaje en las políticas migratorias y en el clima político en el que fueron realizadas. Como bien afirma Isis Saavedra: "El binomio frontera-cine se debe entender como una construcción conformada a partir de la combinación de una serie de circunstancias históricas, políticas y sociales que trascienden la vida cotidiana" (2019, p. 319).

El presente artículo recupera estas ideas y tiene como objetivo analizar el contenido del filme Undocumented (2010) de Chris Peckover. Una película que aborda la travesía de un grupo de migrantes mexicanos que son interceptados y capturados por un grupo de paramilitares nacionalistas estadounidenses. El filme cuenta con un fuerte mensaje en contra de las políticas y legislaciones antimigratorias que se estaban discutiendo en la agenda americana durante la administración de Barack Obama, particularmente la llamada Ley Arizona o ley SB1070. Además de representar el clima político-migratorio del momento, su diégesis expone los riesgos que los migrantes enfrentan, al día de hoy, en el cruce de un país a otro, todo esto buscando abrir el debate y exaltar las violaciones a los derechos humanos que están teniendo lugar en la frontera.

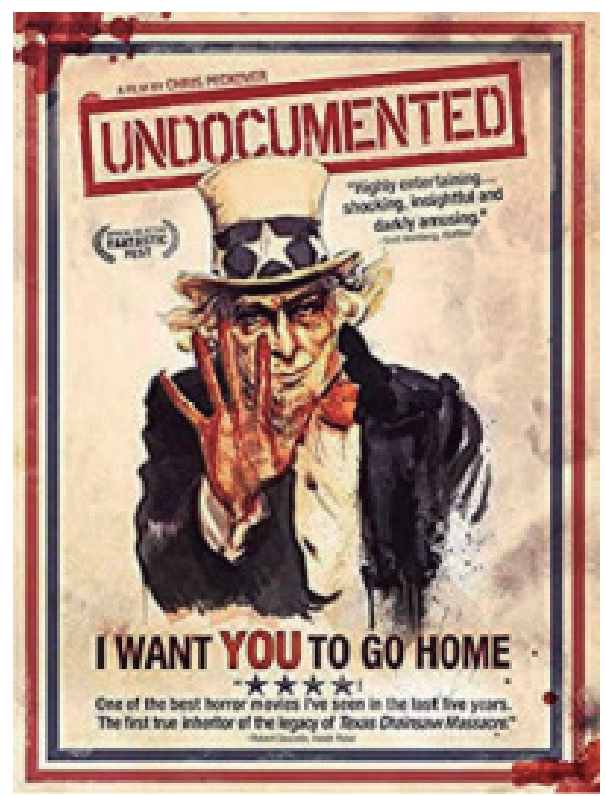

La problemática de Undocumented es vigente en el contexto migratorio contemporáneo, donde las voces 
xenófobas y racistas - teniendo como vocero en muchas ocasiones al mismo presidente Donald Trump - se han intensificado y endurecido en contra de los migrantes indocumentados, pudiendo considerarla, ya, como una violencia de tipo estructural o sistémica que se encuentra lejos de ser erradicada.

Se comienza presentando un breve panorama de las políticas migratorias que han contribuido al asentamiento de un ambiente racista alrededor del migrante indocumentado, incluso hasta su criminalización. A la vez, este texto explora los principales riesgos - naturales y humanos - a los que se enfrenta el migrante en el cruce fronterizo, mismos que se derivan, en varias ocasiones, de las modificaciones legislativas en torno a la vigilancia en la región. Ya planteados y explorados estos puntos que fungen de marco teórico, procederemos a analizar Undocumented bajo la premisa de que el filme parte del contexto histórico-político-social en el que fue elaborado, para llegar a la construcción de un mensaje crítico en contra de la xenofobia, el racismo y la criminalización del migrante en los Estados Unidos.

\section{Políticas fronterizas, riesgos y violencia hacia el migrante indocumentado}

La migración de indocumentados de México a Estados Unidos se ha incrementado de manera considerable en los últimos años, pese al reforzamiento de las medidas de seguridad fronteriza y al mismo clima antimigratorio que se ha promovido en varios de los estados americanos colindantes con el territorio mexicano. Entre 2005 y 2012, el promedio de migrantes de origen mexicano que intentaban cruzar la frontera era de 570,000 personas al año, aproximadamente (Orraca Romano y Corona Villavicencio, 2014, p. 13). Los años siguientes, las cifras continuaron aumentando sin poder identificar una tendencia a la baja. Incluso, en la primera mitad del año 2020 , pese a la crisis sanitaria derivada de la epidemia del Covid-19, el flujo migratorio continuó sin grandes variaciones respecto a los mismos meses en años previos. En la siguiente tabla se presenta el panorama estadístico de los últimos años tomando como referencia el número de migrantes que han sido detenidos por la patrulla fronteriza estadounidense. Cabe recalcar que resulta imposible tener un control numérico de los migrantes indocumentados que logran cruzar exitosamente la frontera, así como de quienes no lo consiguen o mueren durante el proceso. Aunque las cifras a continuación incluyen de-

\begin{tabular}{|cc|}
\hline $\begin{array}{c}\text { Ano fiscal estadounidense } \\
2020 \text { (octubra-jurio) }\end{array}$ & $\begin{array}{c}\text { Migrantes detenidos por la } \\
\text { patrulla fronteriza }\end{array}$ \\
\hline 2019 & 259,147 \\
\hline 2018 & 977,509 \\
\hline 2017 & 521,090 \\
\hline 2016 & 415,517 \\
\hline 2015 & 553,378 \\
\hline
\end{tabular}

tenciones de personas que no son de origen mexicano, nos presentan un panorama base para reflexionar sobre la situación:

Tabla1. Migrantesindocumentados detenidos por lapatrulla fronteriza.Elaboración propia con información de U.S. Customs and Border Protection.

Ahora bien, las causas de las migraciones son diversas y han sido estudiadas en múltiples espacios y desde varias perspectivas (Aruj, 2008; Suárez Núñez del Prado, 2008; Castles, 2010; Celis Sánchez y Aierdi Urraza, 2015), pudiendo sintetizar que:

La pobreza, la violencia, la inseguridad, la impunidad, la corrupción son elementos que [...] [los migrantes] señalan como elementos básicos que justifican su migración a E.E.U.U. [...]. A esto se suman nuevos eventos como las fuertes crisis económicas regionales y los desastres naturales provocados por huracanes, inundaciones y terremotos [...]. Pero, sobre todo, son decisivas las inversiones en plantas hidroeléctricas, presas y proyectos ecoturísticos que están destrozando las comunidades indígenas, las tradiciones y la herencia cultural de dichas comunidades [...]. La violencia de género y los feminicidios en Centroamérica y México son una parte fundamental del régimen de movilidad sufrido por las mujeres, al ser causa y característica del proceso migratorio de las mujeres (Cortés, 2018, pp. 41-42).

En muchos de los casos, paradójicamente, "migrar puede ser más seguro que quedarse en sus barrios y pueblos" (Cortés, 2018, p. 47), pese a los consabidos riesgos del trayecto y la frontera. Siguiendo esta misma línea, Eduardo Torre-Cantalapiedra señala que los migrantes son víctimas de una dinámica compleja de violencia estructural, [1] que se manifiesta en diferentes momentos del proceso migratorio (a través del hambre, los riesgos de salud, la exclusión y el racismo, por ejemplo): "primero como motivo de la migración; segundo, en el tránsito de territorios y en el cruce de fronteras internacionales; tercero, en relación con la violencia postestructural [2] que padecen en el tránsito; y cuarto, en relación con la violencia legal que dificulta la integración en la sociedad de acogida” (2019, p. 87). 
Aunque siempre han existido riesgos al momento de cruzar la frontera a Estados Unidos desde el territorio mexicano; éstos se han intensificado con el surgimiento de nuevos operativos fronterizos (Feldmann y Durand, 2008, p. 12) que han contribuido a la creación de un entorno racista y hostil en la franja fronteriza.

A finales de la década de 1980, el gobierno estadounidense aumentó presión a México con el fin de que vigilara su frontera, debido al constante aumento en el flujo de indocumentados. Buscando revertir esta tendencia, el mandato de Ronald Reagan aprobó en 1986 la Immigration Reform and Control Act (IRCA), política que otorgaba amnistía a la población indocumentada residente en los Estados Unidos. El acta legalizó a más de 3.2 millones de indocumentados de los cuáles más de 2 millones eran mexicanos (Massey, Durand y Malone, 2002). Empero, esta medida trajo consecuencias opuestas a las esperadas por el gobierno americano, puesto que la migración aumentó por una ola conformada, en su mayoría, por las familias de los individuos que habían sido legalizados y que buscaban reunirse con ellos bajo su nuevo estatuto legal (González Reyes, 2009, p. 50).

La migración mexicana hacia el norte continuó sin mayores alteraciones en su ritmo tras la aprobación de la IRCA. Mientras tanto, los países del Triángulo Norte de Centroamérica (TNC) - Guatemala, Honduras y El Salvador - incrementaron de manera considerable el flujo migratorio hacia los Estados Unidos, como consecuencia de los conflictos armados de sus países, la pobreza y otras situaciones ya referidas con anterioridad. La posición americana con respecto al gran volumen de migrantes que in ${ }^{\text {gre }}$ saban al país adquirió mayor rigor, solidez y agresividad en la década de los 90 , durante el mandato de Bill Clinton.

La estrategia estadounidense para hacer frente al ingreso de migrantes indocumentados a su territorio se inclinó ahora hacia la disuasión y el temor. En 1993, en El Paso, Texas, se implementó un programa piloto que recibió el nombre de Operación Bloqueo (Hold-theLine) que consistía, grosso modo, en militarizar y vigilar con numerosas unidades los cruces habituales de la frontera, con el fin de interceptar a los migrantes ilegales que optaran por estas vías (Feldmann y Durand, 2008, p. 16). Paralelamente, ante el aumento de vigilancia en esto puntos bien identificados, los migrantes se verían obligados a tomar rutas "alternas" para llegar al país del norte, rutas que se caracterizaban por inclemencias climáticas (desiertos), cuerpos de agua que difícilmente podrían cruzarse a nado (el Río Bravo) o animales venenosos (serpientes y alacranes, principalmente). De esta manera, se imponían barreras naturales para impedir la llegada de los migrantes. Con estos nuevos riesgos sumados a la "aventura" fronteriza y mediante la difusión de considerables cifras de migrantes que morían en el trayecto, se pretendía que los aspirantes a ingresar sin documentos a Estados Unidos fueran disuadidos a través del temor (prevention through deterrence).

Este modelo antimigratorio fue replicado e implementado en varias ciudades fronterizas: en California (Operation Gatekeeper), en Arizona (Operation Safeguard), en Ciudad Juárez-El Paso (Operation Hold the Line) y en el sur de Texas (Operation Rio Grande) (Trujeque Díaz, 2007, p. 143). Ante el aumento de la vigilancia en los cruces urbanos habituales, la migración situó sus bases en sitios despoblados o rurales. Mientras Baja California perdió importancia en este rubro, estados como Sonora adquirieron mayor relevancia y flujo de migrantes. A la par, las aprehensiones de indocumentados en los Estados Unidos disminuyeron de manera considerable, pero las muertes y rescates aumentaron exponencialmente (Meneses, 2005, p. 119).

La política estadounidense que se basa en la disuasión ha perdurado hasta la actualidad y ha sido ampliamente criticada desde la perspectiva de los derechos humanos, bajo la hipótesis de que en esta práctica subyace un cuestionable darwinismo social que asegura la supervivencia de los más aptos. Como bien señalan Feldmann y Durand, esta política migratoria estadounidense:

Busca de manera explícita disuadir a los migrantes de cruzar la frontera al aumentar los costos y los riesgos del cruce irregular. Al desviar los flujos migratorios hacia áreas más agrestes y desoladas donde el cruce de la frontera encierra evidentes riesgos, las autoridades estadounidenses están sometiendo a los migrantes a una especie de darwinismo social en el que sólo los más fuertes y con mayores recursos logran sortear los peligros del cruce y llegar a su destino [...]. Tanto en términos del derecho internacional como de los derechos humanos, existe un vacío legal que impide promover la protección de la población migrante (2008, p. 13).

Durante los gobiernos de George W. Bush (20012009) y de Barack Obama (2009-2017) se invirtieron muchos recursos para reforzar la patrulla fronteriza y se incorporaron nuevas tecnologías para detectar y rastrear indocumentados, en gran medida, debido al aumento de la violencia en el norte de México y al 
incremento de poder de cárteles de narcotraficantes (González Reyes, 2009, p. 50). ${ }^{[3]}$

En la administración Obama se reafirmaron los intereses americanos con respecto a la seguridad fronteriza: "mantener el reforzamiento de sus fronteras; proveer el equipo más sofisticado para el control y la vigilancia antidrogas; mantener la cooperación en cuanto a la seguridad y combate a las drogas y al terrorismo de México y considerar el respeto a los derechos humanos" (Ramos García, 2012, p. 10). Estos objetivos quedaron plasmados en la Iniciativa Mérida y en el Plan de Seguridad Fronteriza Regional (2010), ambos proyectos buscaban reafirmar la cooperación entre las dos naciones por la seguridad de la frontera y la erradicación del tráfico de drogas.

De manera paralela a las políticas federales estadounidenses relacionadas con la migración y la frontera, en los estados del sur - específicamente Arizona - se exacerbaban el racismo y la xenofobia disfrazados de un sentimiento nacionalista que buscaba velar por la seguridad del pueblo americano frente a la amenaza que representaba, bajo su óptica, el migrante indocumentado. Con la guerra contra el narcotráfico en México y la violencia en el país del sur como antesala, el senador republicano Russell Pearce propuso en Arizona (2008) el proyecto de ley SB1070, que pretendía defender al estado de los indocumentados, considerados como criminales. En abril de 2010, la gobernadora de Arizona, Jan Brewer aprobó la ley que entró en vigor ese mismo año (Grageda Bustamante, 2018, p. 7).

La ley SB1070 establece, de manera general: 1) la criminalización del migrante indocumentado; 2) la autorización a los agentes de la policía estatal para revisar la documentación y la condición migratoria de las personas ante cualquier sospecha razonable por parte del agente, sin la necesidad de una orden judicial; 3) la detención de las personas de aspecto "sospechoso" para llevar a cabo los interrogatorios y averiguaciones pertinentes ante cualquier irregularidad; 4) la obligación de todo extranjero a portar su documentación migratoria en todo momento; 5) la sanción de cualquier individuo implicado en el traslado, movilidad, apoyo o empleo de migrantes indocumentados (Arizona SB1070, 2010).

Esta ley fue ampliamente criticada tanto en México como en Estados Unidos por sus tintes xenófobos y racistas, llegando a ser equiparada con las acciones tomadas en contra de los judíos durante la Segunda Guerra Mundial. Empero, como se verá párrafos más adelante y en el mismo análisis del filme Undocumented, varios rancheros y grupos nacionalistas americanos celebraron la aprobación de la ley SB1070 llegando a impartir "justicia” por sus propias manos bajo el cobijo de lo enunciado en la legislación.

En el mandato de Donald Trump, el indocumentado continúa siendo criminalizado y se ha reforzado la vigilancia fronteriza para impedir el acceso de migrantes mediante la ampliación del muro entre ambas naciones, ha habido un aumento considerable de los miembros que conforman la patrulla fronteriza y se han incorporado nuevas tecnologías - drones, por ejemplo - para la detección de migrantes (Lee, 2018, p. 224). A la par de estas medidas, el discurso xenófobo que caracterizó a los defensores de la ley SB1070 parece ser compartido por el mismo presidente, quien desde su campaña dejó clara su postura de cero tolerancia a los migrantes indocumentados, considerándolos como enemigos de la soberanía americana y reafirmando la criminalización de los mismos bajo la falacia de que se trata, siempre, de bad hombres.

Como pudimos ver, de manera sucinta, las políticas migratorias de los últimos cuarenta años no han sido capaces de frenar el flujo de migrantes indocumentados. En su lugar, estas estrategias únicamente han obligado a los "inmigrantes a pagar tarifas más altas a polleros y coyotes y a enfrentar peligros y riesgos de muerte, accidentes, violación, asaltos, estafas, vejaciones, etc. En resumidas cuentas, han construido las circunstancias violentas como parte de la estrategia para disuadir a los indocumentados" (Meneses, 2005, p. 124).

Una vez expuesto este panorama general de las políticas migratorias, indispensable para poder situar ideológica, contextual e históricamente al filme $U n$ documented, presentaremos brevemente cuáles son los riesgos a los que se enfrentan los migrantes indocumentados al momento de cruzar la frontera México-Estados Unidos, y que son recuperados en la diégesis del filme.

Como ya mencionamos, resulta muy complicado contar con cifras precisas sobre las muertes de migrantes en su trayecto a Estados Unidos. Para el año 2012, se registraron según algunas estimaciones cerca de 500 defunciones (Orraca Romano y Corona Villavicencio, 2014, p. 14), pero es muy factible que esta cifra sea superada en realidad por varios cientos más de migrantes que pierden la vida y cuyos cuerpos no son recuperados. Ante todo, el cruzar la frontera está asociado - en gran parte gracias a los operativos americanos y la estrategia de disuasión - con un gran peligro y un gran índice de fracaso en la misión (Lee, 2018, p. 212). 
Los riesgos a los que se enfrentan los migrantes pueden ser vistos como manifestaciones de la violencia estructural en la que se encuentran inmersos involuntariamente por su misma situación de otredad. Las amenazas pueden dividirse en aquéllas de tipo natural y las de tipo humano. Entre las primeras figuran situaciones climáticas que pueden enfermar y conducir a la muerte al migrante, como la deshidratación y la hipotermia; así como otras relacionadas con el ecosistema y la geografía de la región del cruce fronterizo, donde destaca el ahogamiento en el Río Bravo o las muertes por envenenamiento como consecuencia de la picadura o mordedura de un animal venenoso (Feldmann y $\mathrm{Du}-$ rand, 2008, p. 20).

Además de sortear los obstáculos de la naturaleza misma, los migrantes se enfrentan también a amenazas humanas. Tal es el caso de los grupos criminales y de los cárteles de narcotraficantes, quienes ven en los migrantes a potenciales víctimas de sus respectivas dinámicas delincuenciales. En su trayectoria, los indocumentados se suelen encontrar con criminales que se distinguen por robarlos, secuestrarlos y violarlos, muchas veces en contubernio con los coyotes (Meneses, 2005, p. 123). La Comisión Nacional de los Derechos $\mathrm{Hu}-$ manos (CNDH), desde 2009, emitió una alerta ante el creciente número de secuestros de migrantes que estaba teniendo lugar en el país, contabilizando más de 9,758 casos - en ese año- de desapariciones forzadas (Ramos García, 2012, p. 25). Asimismo, como un reflejo de la violencia postestructural, los migrantes que han sido interceptados por la patrulla fronteriza y deportados de regreso a México, frecuentemente sin dinero ni documentos oficiales, tienden a ser blancos fáciles de secuestradores o candidatos a ser reclutados por los grupos criminales (Lee, 2018, p. 215).

En lo que respecta a los cárteles, sobre todo los Zetas, se han posicionado en la ruta habitual de los migrantes, aprovechando que es también la vía que utilizan para el tráfico de drogas. En ocasiones, estos grupos, conocedores de la zona, interceptan "a los migrantes para extorsionarles, secuestrarles y pedir dinero a la familia y/o secuestrar a las mujeres y forzarlas a entrar en redes de trata y prostitución" (Cortés, 2018, p. 50). Baste como ejemplo la masacre de 72 migrantes indocumentados en agosto de 2010, conocida como la masacre de San Fernando (De Alba, 2019).

Otra amenaza humana que acecha a los migrantes son los denominados cazadores de indocumentados. Se trata de grupos paramilitares estadounidenses - en su mayoría rancheros de los estados del sur- que, partiendo de un discurso racista y nacionalista, se organizan para llevar a cabo cacerías de migrantes buscando impartir justicia por su propia mano, ante la ineficiencia de la patrulla fronteriza, justificando sus acciones como defensa propia. Estos grupos tienen sus orígenes en los atentados terroristas del 11 de septiembre de 2001, contexto donde surgió la asociación Ranch Rescue, con el objetivo de "defender las propiedades privadas de los intrusos que las traspasan, fuesen migrantes o narcotraficantes [...]. Esta organización paramilitar, desde 2001, ha establecido capítulos o sedes en siete estados: California, Arizona, Nuevo México, Texas, Colorado, Missouri y Oklahoma" (Trujeque Díaz, 2007, p. 144).

Ranch Rescue sirvió de modelo para la creación de otros grupos con el objetivo de detener los flujos migratorios, a la par de las medidas y estrategias tomadas por el gobierno, y de vigilar la zona. En la primera década del siglo XXI surgieron agrupaciones similares como Minuteman Project, Border Rescue, Civil Homeland and Defense y American for Zero Immigration; agrupaciones que subrayaban "el carácter voluntario, civil y 'pacífico' de sus acciones, [donde] su táctica de no establecer contacto físico con los supuestos invasores les ahorraba la acusación de ser violadores de los derechos humanos" (Trujeque Díaz, 2007, p. 146). ${ }^{[4]}$

La ley SB1070, acentuó el discurso xenófobo y racista existente, por encima del supuesto "pacifismo" de estas agrupaciones nacionalistas. Sobran casos en los que estos grupos ejercen violencia física y verbal hacia los indocumentados, llegando a cazarlos - en el sentido literal de la palabra - bajo el argumento de "purificar" y "defender" a su patria y su propiedad privada (Orraca Romano y Corona Villavicencio, 2014, pp. 15-16). La ideología de estos grupos paramilitares que aún continúan coordinando cacerías, mediante el uso de las redes sociales, es uno de los temas centrales desarrollados en el filme Undocumented.

En este recorrido por las estrategias y políticas migratorias seguidas por los Estados Unidos y por los riesgos a los que se enfrentan los migrantes en el cruce fronterizo se ha evidenciado, ante todo, la situación de vulnerabilidad en la que se encuentra este grupo de personas incapaz de sortear la violencia estructural que viola sus derechos humanos. Al mismo tiempo, el reforzamiento legal estadounidense que criminaliza al inmigrante trae consigo un incremento notable de violencia en su contra, volviéndolos el blanco predilecto 
de los grupos antimigrantes presas de la xenofobia y el racismo. Como bien menciona Alison Elizabeth Lee: "la [condición] de ilegalidad deshumaniza a las personas, criminaliza sus movimientos fuera de los canales autorizados, establecidos por la política migratoria de Estados Unidos y las somete a violencia física y psicológica” (2018, pp. 215-216). En síntesis, se puede afirmar que el migrante indocumentado se encuentra en una espiral de violencia de la que difícilmente podrá librarse a pesar de haber logrado cruzar exitosamente la frontera, una violencia de tipo estructural que se manifiesta a través de un discurso racista y que se encuentra sustentada, a la vez, en una violencia epistemológica y jurídica, cuya consecuencia es la vulneración de los derechos humanos de los migrantes, ignorados por estas políticas y leyes concebidas desde una óptica xenófoba y racista que se niega a reconocer la otredad.

\section{Undocumented, ecos cinematográficos del racismo y el maltrato al migrante}

Habiendo planteado ya el panorama político-migratorio de los últimos años y los riesgos y abusos a los que se ven sometidos los migrantes en la búsqueda de mejores oportunidades de vida, continuamos con el análisis de la película Undocumented del director Chris Peckover. Se trata de una producción estadounidense enmarcada en el subgénero del terror conocido como torture-porn ${ }^{[5]}$ que aborda de manera cruenta y mordaz, pero realista, tras la debida documentación y cimentación política, la realidad a la que se enfrentan los migrantes al momento de cruzar la frontera.

La trama se centra en un grupo de jóvenes documentalistas estadounidenses que desean filmar la odisea de un grupo de migrantes mexicanos que pronto cruzarán la frontera con ayuda de un coyote. Sin embargo, la situación se sale de control cuando son interceptados por un grupo paramilitar americano que secuestra al grupo de migrantes en un matadero de ganado que ha sido adecuado como prisión y cámara de tortura. Gran parte de la diégesis se concentra en la exposición de la ideología de este grupo nacionalista - una representación de los cazadores de migrantes descritos en el apartado anterior - que supone estar haciendo un gran favor a su país al combatir con sus propias manos el fenómeno migratorio, cobijados, impulsados y animados por los cambios legislativos recientes, un evidente eco cinematográfico a la ley SB1070.

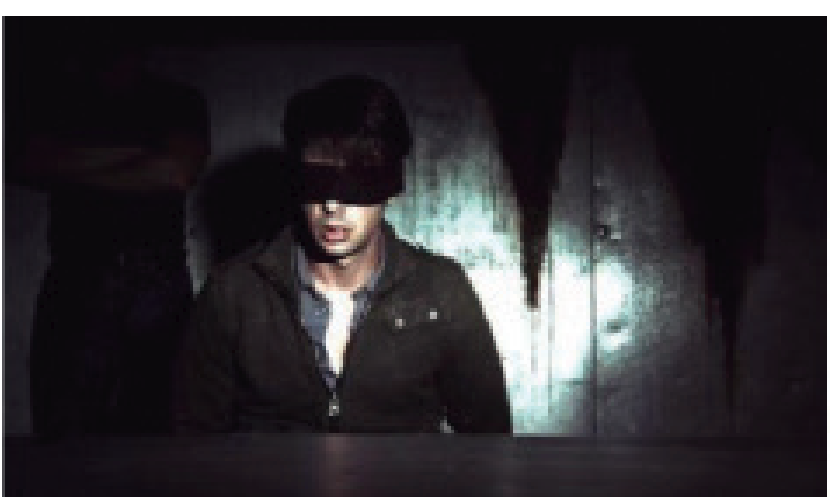

Para realizar el análisis del contenido de Undocumented tomamos en consideración cuatro grandes bloques temáticos a estudiar partiendo de lo expuesto en el marco teórico, a través de un entrecruzamiento entre la realidad migratoria y lo representado en este filme: 1) la descripción de los migrantes que hace la cinta; 2) el viaje del migrante y el cruce de la frontera; 3) la representación del clima de xenofobia, odio frontal y racismo que recae en el grupo paramilitar; 4) así como la postura ideológica y política de los realizadores - el mensaje o la toma de posición - con respecto a la migración.

Desde su primera secuencia, la película de Peckover expone el contexto sociopolítico y el discurso sobre el que se construye gran parte de la trama. Se presentan varios fragmentos de vídeo, fotografías reales y audios de los debates políticos en torno a la migración durante la administración de Obama, haciendo énfasis en los debates y propuestas de leyes en Arizona que culminaron en la aprobación de la ley SB1070 en 2010, año de producción y estreno de la cinta.

Tras esta breve introducción al contexto, el filme se concentra en las entrevistas del grupo de documentalistas a quienes pronto cruzarán la frontera. Estas escenas presentan a individuos en precarias condiciones económicas, sociales y laborales que desean dar un giro radical a su vida, viendo una latente oportunidad de empezar de cero y con mejores oportunidades cruzando la frontera. Se podría considerar que Peckover, realiza una breve exposición del perfil de quienes deciden abandonar su país rumbo a los Estados Unidos.

El grupo de migrantes está conformado por personas de diferentes edades, desde niños hasta adultos mayores; algunos viajan en solitario o en familia; para algunos se trata de su primera vez intentando cruzar la frontera, para otros es ya el tercer intento. Todos tienen en común la pertenencia a sectores marginados de la población mexicana (víctimas de violencia estructural 
y extrema pobreza). Asimismo, comparten el deseo y la esperanza de iniciar una vida mejor en Estados Unidos, lejos de sus respectivas problemáticas envueltos en la narrativa de la leyenda negra y las idealizaciones del sueño americano; esto último se evidencia por su firme creencia en la transformación inmediata de su vida tan pronto abandonen México. Poco conocen realmente al país del norte y al mismo tiempo están dispuestos a ingresar a un sitio ajeno, sin conocer el idioma ni la cultura, un país al que sólo conocen a partir de imaginarios idílicos y generalizaciones -Disneylandia, Hollywood, entre otros - que seguramente provienen de los medios de comunicación. Ante esta situación, Peckover representa al migrante que está dispuesto a arriesgarlo todo - dinero, familia y su vida mismacon el fin de llegar a los Estados Unidos, país al que ve como una tierra de oportunidades que cambiará su vida para bien y definitivamente.

Después de la presentación del perfil de los migrantes, Undocumented prosigue con el inicio de la travesía hacia los Estados Unidos. Los documentalistas acompañan al grupo de migrantes que han invertido todos sus ahorros en un coyote que les ofrece una ruta segura rumbo al país del norte. Todos han preparado una mochila con lo indispensable para sobrevivir el recorrido, principalmente agua y ropa. Tras haber sido conducidos en un camión por el desierto mexicano hasta la franja fronteriza, el coyote los guía hacia un túnel oculto en la vegetación que será la vía por la cual cruzarán al otro lado. Por los diálogos sabemos que se trata de un túnel creado secretamente y utilizado por el narcotráfico para introducir la droga a Estados Unidos, situación que evidencia la estrecha relación entre los grupos criminales y el coyotaje.

Con la ayuda de linternas, los migrantes cruzan el túnel guiados por el coyote. En el trayecto se encuentran con cadáveres de otros migrantes, lo que genera un gran impacto en el grupo, a tal grado que algunos de ellos dan la media vuelta para regresar a territorio mexicano. Estas escenas claramente aluden a la política de disuasión defendida por la estrategia migratoria estadounidense. Quienes siguen adelante en el recorrido se ven obligados a permanecer ocultos cerca de la carretera en espera de un camión que los conducirá hacia una "casa segura". Ya en el vehículo, los migrantes y los documentalistas deben competir por el poco espacio que hay en la cabina de carga y turnarse para poder respirar a través de pequeños orificios en la carrocería del camión. 6

No obstante, el camión es interceptado y se sugiere que el coyote es asesinado. Los migrantes, en evidente estado de pánico, son obligados a descender del vehículo por el grupo de paramilitares que los ha capturado. Este momento marca el fin del viaje migratorio por la frontera y da inicio a la representación de xenofobia y racismo que se manifiesta en estos individuos. Desde el primer encuentro entre ambos grupos, paramilitares y migrantes, los primeros se posicionan como quienes ejercen el poder y control sobre los segundos, a quienes, de inmediato, buscan doblegar e intimidar mediante la presencia de armas. Llama la atención el hecho de que los hacen desnudarse frente a ellos, dejándolos completamente expuestos y vulnerables, tanto física como psicológicamente.

De manera inmediata, los documentalistas, por ser estadounidenses, son separados de los migrantes. Éstos gozarán de mejores "atenciones" por parte de los cazadores de migrantes, pudiendo dormir sin cadenas ni ataduras en una habitación donde se ha apilado la ropa de cientos de migrantes que han sido prisioneros de los paramilitares. Asimismo, los documentalistas pueden alimentarse con la misma comida que sus captores, mientras que los indocumentados deben comer en el piso como si de ganado se tratara. Este trato desigual deja en claro que el objetivo-víctima de los cazadores no es cualquier individuo que se encuentre en su camino, sino que se trata de una búsqueda específica con fundamento en su ideología nacionalista extremista con la cual, en sus propias palabras, buscan "recuperar y sanar" a su país erradicando el mal que lo aqueja: el migrante indocumentado (Peckover, 2010).

Paralelamente, los cazadores dan un trato especial a los documentalistas con dos objetivos principales: 1) intentar convencerlos de que se encuentran haciendo lo correcto al exterminar la amenaza que aqueja a su país y, posiblemente, incorporarlos como adeptos a su ideología; 2) así como para que filmen lo que ocurre dentro de las paredes del matadero de animales y sea difundido en México, sirviendo de muestra de lo que puede ocurrir con quienes cruzan la frontera de manera ilegal. En el segundo punto, se identifican nuevamente las características de la estrategia de disuasión como vía de combate a la migración que ha seguido la política americana desde la década de 1990, pero esta vez con énfasis en un "mensaje” más visceral y más explícito para que no quede duda de que el grupo paramilitar no se toma a la ligera el problema migratorio. 


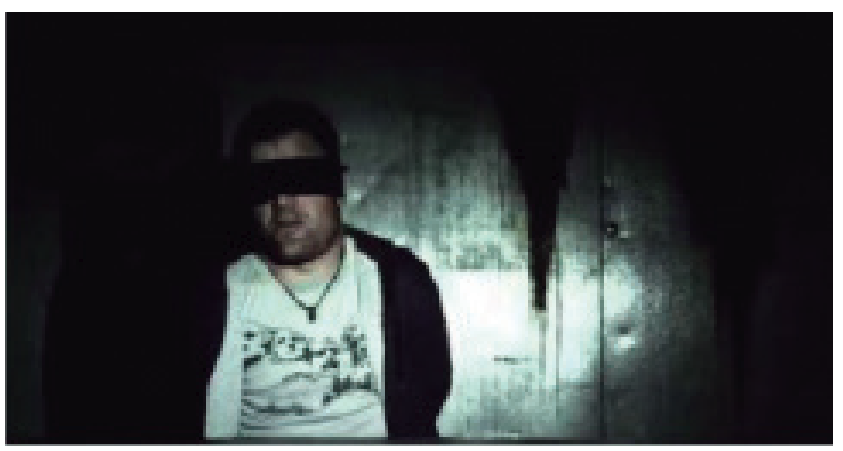

Siendo obligados por el líder de los cazadores, los documentalistas se adentran, al igual que el espectador, a sus prácticas xenófobas y racistas, convirtiéndose en testigos de los abusos cometidos en el rastro. En primera instancia se enfrentan a la separación de las familias que conformaban el grupo de migrantes con el cual atravesaron la frontera. Bajo la falsa idea de que los paramilitares son "humanos" y "solidarios", permiten que los menores de edad abandonen por su propio pie el lugar y regresen a México; sin embargo, como bien se revela en la diégesis, el fatídico desenlace de los niños es el mismo. Los infantes pueden haberse librado de ser torturados y, posteriormente, asesinados por los cazadores, pero pronto perecerán en el desierto como consecuencia del clima, del hambre, de la deshidratación o de los otros riesgos ya mencionados. Al igual que sucede con las operaciones de bloqueo implementadas a finales del siglo XX, los captores llevan a la práctica una especie de darwinismo social donde la naturaleza misma y las aptitudes del individuo ponen a prueba su supervivencia, lo que resulta prácticamente imposible al tratarse de niños pequeños.

La separación familiar forzada prosigue en el rastro a partir del género. Las mujeres son separadas de los hombres, esto para ser esclavizadas en quehaceres domésticos (cocinar, limpiar, etc.) al servicio de los paramilitares. De igual manera, se sugiere que son abusadas sexualmente e involucradas en redes de trata de personas. Por su parte, los migrantes varones permanecen encadenados y son sometidos a numerosas torturas y actos denigrantes, siendo en ellos en quienes recae gran parte de la carga violenta explícita del filme.

Los documentalistas presencian, específicamente, cinco momentos cruciales en los que los cazadores "imparten" justicia a los migrantes castigándolos "por el mal y el daño" que ocasionan a la nación. Es importante destacar que estos actos tienen un sustento en una ideología nacionalista extremista xenófoba, como bien se menciona en los diálogos, que considera al migrante indocumentado como un individuo que contamina el piso por el que camina y que ha llegado a terminar con la estabilidad y paz, que alguna vez existió en los Estados Unidos.

El primero de estos momentos tiene lugar el mismo día en que los documentalistas arriban al rastro. Los protagonistas son conducidos por los cazadores a una habitación donde un migrante es inmovilizado en una silla. El líder de los paramilitares explica que el $90 \%$ de la droga que circula en el país proviene de México y que ésta, en muchas ocasiones, es introducida en el interior del cuerpo de las mujeres, llamadas "mulas", que ingresan a la nación. Acto seguido, procede a obligar al migrante aprisionado a deglutir un preservativo que contiene droga en su interior, como si a través de esta tortura al individuo se enviara un mensaje a quienes introducen los narcóticos a Estados Unidos.

En la segunda situación, las víctimas son los padres de una niña que ha sido "liberada" por sus captores para que cruce el desierto en busca de su camino hacia México. Los paramilitares colocan a la madre en un artefacto de tortura similar a los potros utilizados en tiempos de la inquisición, mientras que su esposo permanece atado en una silla. Bajo la premisa de que los migrantes indocumentados no "merecen" pertenecer a los Estados Unidos debido a que ignoran por completo la cultura, la ley, la historia y el idioma del país, los cazadores proceden a realizar tres preguntas que consideran básicas para cualquier individuo que aspire a convertirse en un estadounidense. En este caso, las preguntas son dirigidas al migrante varón, quien siendo incapaz de responder los cuestionamientos porque desconoce el idioma, "causa" tortura física a su esposa con cada uno de sus errores. El mensaje que los paramilitares buscan transmitir a los migrantes es que no han de ingresar a un país sin conocer siquiera lo fundamental, el castigo implementado a estos dos individuos, pretende servir como exhortación a abandonar la empresa de cruzar a ciegas la frontera.

Las medidas de disuasión se exponen también en el tercer momento desarrollado en Undocumented. Los documentalistas son conducidos a una habitación que funciona a manera de morgue. Ahí, un excéntrico paramilitar disfruta mostrándoles sus "obras de arte". Este individuo se dedica a trabajar con los cadáveres de los migrantes que han muerto en el lugar con el fin de convertirlos en una especie de espantapájaros humanos, mismos que serán situados en sitios clave de las rutas de los indocumentados para que - tal y como ocurrió en el túnel en el inicio de la cinta - asusten a los migrantes y se conviertan en una advertencia de lo que puede ocurrirles de seguir adelante con su empresa. 
Durante la cuarta situación, los paramilitares parten de la falsa creencia de que los migrantes indocumentados no aportan a los Estados Unidos, considerando que en muchas ocasiones se convierten en una carga o peso muerto que los ciudadanos legítimos terminan costeando a través de sus impuestos. Buscando alguna utilidad para la nación, proceden a extraer los órganos útiles de los cuerpos migrantes con el fin de realizar trasplantes a los ciudadanos americanos que así lo necesiten. El líder de los cazadores deja claro que no buscan obtener dinero al vender los órganos en el mercado negro, sino que realizan estas operaciones con la única finalidad de salvar vidas de ciudadanos "legítimos" y "legales".

Finalmente, el quinto y último momento concentra en su máxima expresión la xenofobia y el menosprecio hacia el migrante indocumentado, al mismo tiempo que se denigra por completo a estas personas sometiéndolas a burlas racistas sobre sus orígenes y tradiciones. Los documentalistas sobrevivientes son llevados a una habitación que ha sido adornada y decorada como una fiesta típica mexicana; los migrantes prisioneros se encuentran atados y disfrazados de mariachis, chinas poblanas y de chiles; de fondo se escucha música folclórica mexicana; uno de los documentalistas es obligado a participar rompiendo una piñata que ha sido colgada en el centro del cuarto, utilizando un bate con clavos en la punta. Tras unos cuantos golpes a la piñata descubre que en su interior ha sido colocada una persona, que sangra como consecuencia de las heridas infligidas por el bate.

La escena de la piñata puede ser considerada como el epítome del racismo del grupo paramilitar y de su odio hacia los migrantes. Ante sus ojos, la cultura mexicana no tiene valor y los mexicanos son considerados seres inferiores, primitivos y poco valiosos. Ante estas ideas, son merecedores del trato que les dan en el rastro. Los cazadores no muestran un ápice de misericordia, ni siquiera conservan dudas morales sobre sus actos violentos y denigrantes, sino que, amparados en su ideología nacionalista extrema, están cien por ciento convencidos de producir un verdadero bien a su país.

Además de las expresiones de violencia física ya revisadas en estos cinco momentos cruciales de la diégesis de Undocumented, el filme representa también la violencia verbal a la que son sometidos los migrantes cautivos. El menosprecio hacia la otredad y el racismo se exponen también en los diálogos cargados de generalizaciones, falacias y estigmas que reflejan la estrechez ideológica de los cazadores, incapaces de comprender la diferencia o aceptarla en sí misma. Por hacer mención de algunos diálogos paradigmáticos, los paramilitares hacen mofa de las familias extensas mexicanas aludiendo a su desconocimiento de los métodos anticonceptivos; se les tacha de ignorantes o inferiores intelectualmente; se hacen burlas en torno a la religión y a las creencias mexicanas; así como a sus costumbres y tradiciones. Todos estos discursos justifican que se les otorgue el trato que los paramilitares consideran propios para el ganado.

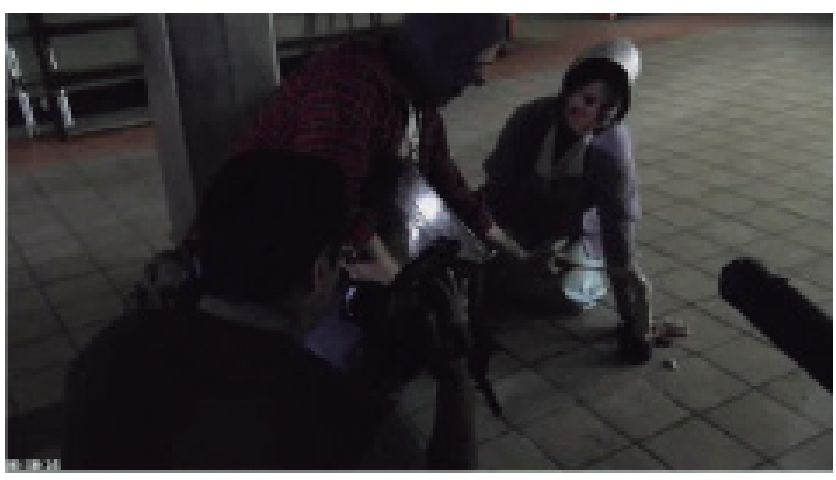

El desenlace de Undocumented resulta poco esperanzador. Los documentalistas sobrevivientes logran liberar a los migrantes cautivos, lo que genera una revuelta en el rastro, sugiriéndose que varios indocumentados escapan con vida. Sin embargo, poco antes de los créditos finales, se presenta al líder de los paramilitares con un grupo de seguidores todavía más grande, dando a entender que existen más adeptos a esta ideología que los representados a lo largo del filme y que la pequeña victoria no resulta significativa. Incluso, en los últimos diálogos, el líder de los cazadores envía un mensaje a los mexicanos acompañado de las torturas filmadas previamente, en el que reafirma su postura con respecto a los migrantes: "Quizás Estados Unidos sea una nación de inmigrantes, pero no es un basurero. Dadme a vuestros rendidos, a vuestros pobres, vuestras masas hacinadas anhelando respirar en libertad y se las devolveremos en pedazos" (Peckover, 2010).

A pesar del alto grado de violencia presentado en el filme y de la continua explotación de la ideología de los grupos paramilitares cazadores de migrantes, la película de Peckover pone de manifiesto que no todos los estadounidenses están de acuerdo con esta postura nacionalista extremista. Los documentalistas intentan frenar los abusos cometidos poniendo en riesgo sus propias vidas y desaprueban los actos de los cazadores. Es en ellos en quienes reside el mensaje crítico de la producción, que se espera sea compartido por el espectador. Al mismo tiempo, ellos pueden considerarse como la brújula moral de la trama y son quienes dejan en claro el posicionamiento 
de los realizadores contra la violencia y racismo explícito hacia los migrantes. Esto último se expresa en uno de los diálogos que dirige una de las documentalistas al líder de los paramilitares, cuando busca demostrarle que los indocumentados también son seres humanos y que jamás merecerán el trato que les dan: "Los inmigrantes ilegales causan crímenes. Transportan enfermedades. Igual que todos los demás. Esto es sólo racismo disfrazado de patriotismo" (Peckover, 2010).

Se puede concluir que Undocumented presenta de manera dura y mordaz los excesos a los que puede conducir una política que otorga fundamento legal al odio y a la xenofobia y que disfraza de patriotismo a un prejuicio racista compartido cuya expresión es cultural, pero cuyo origen es epistemológico, y nos recuerda que el amor a la patria no exige, necesariamente, el desprecio de lo ajeno y que el valor intrínseco de cada ser humano que existe en este mundo es suficiente para brindarle la protección internacional de sus derechos humanos fundamentales, protegiendo su integridad física y su vida, más allá de cualquier frontera.

\section{A manera de conclusión}

Como bien se ha podido apreciar en este texto, las diversas políticas y estrategias estadounidenses, lejos de frenar o desacelerar la migración indocumentada, han desencadenado un clima de xenofobia y racismo manifiesto a través de múltiples expresiones y violacio- nes concretas a los derechos humanos de los migrantes. Entre estas expresiones culturales, que a su vez generan también este clima social, se encuentra precisamente la propia legislación de varios estados del país, responsable de construir y de sostener el prejuicio contra los migrantes indocumentados y promover el incumplimiento de las obligaciones generales que se tienen respecto de los derechos humanos de los migrantes. Estas normativas no cumplen con los requisitos necesarios para imponer límites legítimos para acceder al territorio estadounidense, son desproporcionadas y, a nuestro juicio, forman parte de un sistema de afectaciones ilegítimas constitutivas de responsabilidad internacional para este país que justifica sin dolo alguno el trato diferenciado y humillante e incluso acepta, como si se tratara de un daño colateral derivado de su sistema de seguridad, la muerte y la tortura de miles de inocentes por año.

Undocumented representa con enorme crudeza el panorama poco esperanzador del migrante que abandona su patria en busca de mejores oportunidades, una crudeza que, sin embargo, no lo aparta de la verosimilitud sobre los riesgos reales que conlleva el cruce fronterizo. Chris Peckover logra, a pesar de construir su filme sobre las bases de un género cinematográfico poco frecuentado para la reflexión de los problemas sociales, representar los problemas fronterizos al mismo tiempo que construye una mordaz y certera crítica a la estrategia migratoria estadounidense, dejando en claro que a través del odio y la violencia frontal será imposible hacer a Estados Unidos grandioso de nuevo (Make America great again).

\section{Referencias}

Anónimo (6 de agosto de 2020). U.S. Customs and Border Protection. Estados Unidos: U.S. Department of Homeland Security. Recuperado de https://www.cbp.gov/newsroom/stats/sw-border-migration.

Arizona SB1070 (2010). Senate Bill 1070. Estados Unidos: State of Arizona, Senate, Forty-ninth Legislature, Second Regular Session. Recuperado de https://www.azleg.gov/legtext/49leg/2r/bills/sb1070s.pdf.

Aruj, R.S. (2008). Causas, consecuencias, efectos e impacto de las migraciones en Latinoamérica. En Papeles de Población, 14(55), pp. 95-116.

Calder, J., Calder, K. y Finn, J. (productores) y Peckover, C. (director). (2010). Undocumented [cinta cinematográfica]. Estados Unidos: Sheperd Glen Productions.

Castles, S. (2010). Migración irregular: causas, tipos y dimensiones regionales. En Migración y Desarrollo, 7(15), pp. 49-80.

Celis Sánchez, R. y Aierdi Urraza, X. (2015). ¿ Migración o desplazamiento forzado? Las causas de los movimientos de población a debate. Bilbao, España: Deusto Digital e Instituto de Derechos Humanos Pedro Arrupe.

Cortés, A. (2018). Violencia de género y frontera: migrantes centroamericanas en México hacia los EEUU. En Revista Europea de Estudios Latinoamericanos y del Caribe, (105), pp. 39-60, doi: 10.18352/erlacs.10321.

De Alba, J.I. (23 de agosto de 2019). San Fernando: 72 cruces en el abandono. Pie de Página. Recuperado de https://piedepagina.mx/ san-fernando-72-cruces-en-el-abandono/.

Feldmann, A. y Durand, J. (2008). Mortandad en la frontera. En Migración y Desarrollo, 6(10), pp. 11-35. 
Galtung, J. (1995). Investigaciones teóricas: Sociedad y cultura contemporáneas. Madrid, España: Tecnos.

González Reyes, P.J. (2009). Migración, criminalidad y violencia en la frontera norte de México. En Revista Criminalidad, 51(2), pp. 47-59.

Grageda Bustamante, A. (2018). Arizona contra la inmigración ilegal (ley SB1070); la bivalencia del concepto 'solución final'. En Región y Sociedad, 30(71), pp. 1-42, doi: 10.22198/rys.2018.71.a388.

Izcara Palacios, S.P. (2012). Violencia contra inmigrantes en Tamaulipas. En European Review of Latin American and Caribbean Studies, (93), pp. 3-24.

Jones, S. (2013). The Lexicon of Offense: The meaning of Torture, Porn, and Torture Porn. En F. Attwood et al., Controversial Images (pp. 186-200). Londres, Reino Unido: Palgrave.

Kyle, D. y Dale, J. (2001). Smuggling the State Back: Agents of Human Smuggling Reconsidered. En D. Kyle y R. Kislowski (eds.), Global Smuggling: Comparative Perspectives (pp. 33-59). Baltimore, Estados Unidos: John Hopkins University Press.

Lee, A.E. (2018). US-Mexico Border Militarization and Violence: Dispossession of Undocumented Laboring Classes from Puebla, Mexico. En Migraciones Internacionales, 9(4), pp. 212-238, doi: 10.17428/rmi.v9i35.444.

Massey, D., Durand, J. y Malone, N. (2002). Beyond Smoke and Mirrors. Nueva York, Estados Unidos: Russell Sage Foundation.

Meneses, G.A. (2005). Violencias asociadas al cruce indocumentado de la frontera México-Estados Unidos. En Nueva Antropología, 20(65), pp. 112-129.

Orraca Romano, P.P. y Corona Villavicencio, F.J. (2014). Risk of Death and Aggressions Encountered while Illegally Crossing the U.S.-Mexico Border. En Migraciones Internacionales, 7(3), pp. 9-41.

Ramos García, J.M. (2012). México-Estados Unidos: problemas y retos en seguridad fronteriza en la Administración Obama. En Región y sociedad, 24(55), pp. 5-40.

Saavedra Luna, I. (2019). Frontera Norte: Origen y permanencia de estereotipos, clichés y prejuicios ahí creados. En A. Mondragón González y G. Contreras Pérez (coords.), Paisajes multiversos (pp. 319-337). Ciudad de México, México: Universidad Autónoma Metropolitana.

Slack, J. y Whiteford, S. (2010). Viajes violentos: la transformación de la migración clandestina hacia Sonora y Arizona. En Norteamérica, 5(2), pp. 79-107.

Suárez Núñez del Prado, D. (2008). Causas y efectos de la migración internacional. En Perspectivas, (22), pp. 161-180.

Torre-Cantalapiedra, E. (2019). Violencia, migración y refugio: una mirada reflexiva a contribuciones sobre violencia estructural y movilidad geográfica. En Huellas de la Migración, 4(7), pp. 81-107.

Trujeque Díaz, J.A. (2007). Minuteman Project: Segregación y activismo antimigratorio. En Andamios, 3(6), pp. 137-172.

Velasco Ortiz, L. y Contreras, Ó. (2014). The Border as a Life Experience: Identities, Asymmetry and Border Crossing Between Mexico and the United States. En Frontera Norte. 26. pp. 37-56.

1 Por violencia estructural se puede entender como aquella en la cual no existe un actor o actores identificables, sino que proviene de un sistema institucional o político mismo (Galtung, 1995).

2 El concepto de violencia postestructural es planteado por Slack y Whiteford (2010) y retomado por Izcara Palacios (2016) y Torre-Cantalapiedra (2019), siendo éste último quien la define como aquella violencia en donde "la víctima se convierte en verdugo como única forma de sobrevivir en un entorno de violencia, donde las acciones del individuo están regidas por su lucha de salir con vida de la situación [...]. La violencia es, por tanto, una forma en la que los grupos delictivos reclutan a los migrantes capturados mediante la transformación de sus víctimas en verdugos forzados, a su vez, a emplear la mayor cantidad de violencia para sobrevivir [...]. La violencia postestructural como un mecanismo a través del cual quienes sufren la violencia estructural pueden resultar productores de violencia directa” (p. 97).

3 El fenómeno de la migración a los Estados Unidos ha sido asociada y vinculada con el narcotráfico, lo que representa, también un riesgo para los migrantes. En el norte de México han surgido y se han consolidado varios cárteles de la droga de gran relevancia y peligrosidad, como el cártel de Tijuana, Ciudad Juárez y del Golfo de México. "Esta actividad ilícita opera a nivel de delincuencia organizada en torno al tráfico de drogas, pero su red de operaciones se vuelve más compleja en la medida en que los grupos delictivos amplían su campo de actividad combinándolo con otro tipo de actividades ilícitas rentables, como el secuestro, el lavado de dinero, el tráfico de indocumentados, el contrabando de armas, entre otros más” (González Reyes, 2009, p. 51).

4 Varios de estos grupos han realizado peticiones en política migratoria a las autoridades, mismas que se han convertido en proyectos de leyes apoyadas por el partido republicano (Trujeque Díaz, 2007, p. 147).

5 Este subgénero y término nació en 2006 tras la definición de éste por el crítico David Edelstein haciendo referencia al contenido de las películas Saw: juego macabro (James Wan, 2004) y Hostal (Eli Roth, 2005). Se trata de filmes que presentan en su trama violencia física y psicológica de manera muy explícita y gráfica hasta el punto de convertirla en un punto medular de su diégesis. 
Es frecuente la presentación de torturas, mutilaciones y trampas corporales en las tramas. Entre los directores más destacados del subgénero se encuentran Eli Roth, Joe Lynch, Zev Berman y Rob Zombie (Jones, 2013).

6 En la realidad, un número importante de las muertes de migrantes en el cruce fronterizo tiene lugar en los vehículos. Los coyotes, al sentirse en peligro o al ser descubiertos por la patrulla fronteriza, abandonan los automóviles o camiones dejando a los migrantes encerrados en las cajuelas o compartimentos de carga, hasta que éstos terminan asfixiándose, deshidratándose por las altas temperaturas o siendo capturados por las autoridades estadounidenses (Kyle y Dale, 2001). 